\title{
Stroke in Sub-Saharan Africa, from Thrombolysis to Decompressive Craniectomy: Case Report
}

\author{
Ossou-Nguiet PM1,2*, Sossoumihen $\mathbf{L L}^{3}$, Matali \\ $\mathrm{E}^{1}$, Mpandzou GA ${ }^{1,2}$, Motoula Latou $\mathrm{DH}^{1,2}$, Sounga \\ Bandzouzi EP $\mathbf{P}^{2,4}$ and Bandzouzi-Ndamba $\mathrm{B}^{1,2}$ \\ ${ }^{1}$ Department of Neurology, University Hospital of \\ Brazzaville, Congo \\ ${ }^{2}$ Faculty of Health Sciences of Brazzaville, Congo \\ ${ }^{3}$ Clinique Pasteur, Brazzaville, Congo \\ ${ }^{4}$ Department of Neurology, Hospital of Loandjili, Congo \\ *Corresponding author: Ossou-Nguiet PM, \\ Department of Neurology, University Hospital of \\ Brazzaville. 13 Avenue Auxence Ikonga, BP 32. Congo
}

Received: March 21, 2017; Accepted: June 07, 2017; Published: June 22, 2017

\begin{abstract}
The management of ischemic stroke is currently adapted in stroke unit. IV thrombolysis and mechanical thrombectomy are the most effectiveness treatments.

We report the case of 54-year-old patient, who was admitted in our department for sudden left hemiparesis. According to initial examination and CTscan, he needs treatment by IV thrombolysis and mechanical thrombectomy, but in Congo mechanical thrombectomy is not available. He has IV thrombolysis alone, without success. The control CT-scan showed malignant infarction for which thrombectomy was not indicated. The patient died 24 hours after.
\end{abstract}

Keywords: Ischemic stroke; Thrombolysis; Thrombectomy; Sub-Saharan africa

\section{Introduction}

Ischemic stroke has benefited in the last two decades, from an adapted management. Stroke unit, IV thrombolysis and mechanical thrombectomy represent effective treatments in the acute phase [1,2]. Despite stroke mortality rate decreased in high income countries [3], in low income countries stroke mortality becomes higher than that lung or diarrheal infections, tuberculosis, AIDS or malaria [4], contrasting with a lake adequate care management [5]. In Congo, stroke unit was set up in January 2014, with a capacity of 26 beds including 11 intensive care. In the hospital there are an MRI of 1.5 tesla available to $7 \mathrm{AM}$ to $2 \mathrm{PM}$, and scanner of 32 bar available 24/24. But after 2 PM there is no on-site presence of radiologist, who can be called in case of emergency. In our series, just $5.6 \%$ of patients admitted for ischemic stroke where eligible. They not benefit from IV thrombolysis due to the high cost of rt-PA [6]. Before this case, just one IV thrombolysis was performed. There is neither interventional neuroradiologist nor mechanical thrombectomy equipment.

We report a case requiring management by thrombolysis and thrombectomy, whose reflection on a decompressive craniectomy was carried out.

\section{Case Presentation}

It was a 54-year-old patient, obese $(130 \mathrm{~kg})$, hypertensive, without other risk factors. Admitted in the stroke unit, on December 14, 2016, for a sudden left hemiparesis onset at 8:05 AM. The transport was carried out by a private ambulance to hospital at 10:10 AM. The initial neurological examination noted left hemiplegia, dysarthria, homonymous lateral hemianopia and left hemihypoesthesia. The NIHSS score was at 18 . The cerebral CT-scan without injection of the contrast agent, performed at 10:20 AM, that is 2:15 of the beginning showed no early signs, the ASPECT score was at 10/10, but it noted a visible thrombus from the carotid termination to $\mathrm{M} 1$ of right middle cerebral artery (Figure 1). There was no contraindication to IV Thrombolysis, but mechanical thrombectomy was not available. The thrombolysis was started at 10:55 AM that is 2:50 of the beginning.
The door-to-needle delay was 40 minutes. NIHSS score 2 hours after was always at 18. At 10PM, he has a neurological aggravation, NIHSS score: 24, right unilateral mydriasis. Because of the absence of the radiologist on-site in hospital, the control Cerebral CT scan was performed at 11:58 PM (Figure 2A,B) showed a malignant hemispheric infarction, with always visible thrombus. A discussion on a decompressive craniectomy was carried out and rejected because of several raisons: the clinical severity, signs of cerebral herniation and massive infarction at the time of second CT scan, and delay from IV thrombolysis. Death occurred after 24 hours of evolution.

\section{Discussion}

Our case report presents difficulties in accessing to main therapeutics in sub-Saharan Africa. Indeed, stroke unit, IV thrombolysis and mechanical thrombectomy, proved their effectiveness according to the indications, in acute ischemic stroke.

The organization of care in stroke units has proved effective in reducing mortality rate and functional recovery [7]. In high income countries, there are most than stroke units, but stroke center [8] based on scientific evidence from randomized controlled trials, clinical practice guidelines, and expert consensus. But in Sub-Saharan Africa,

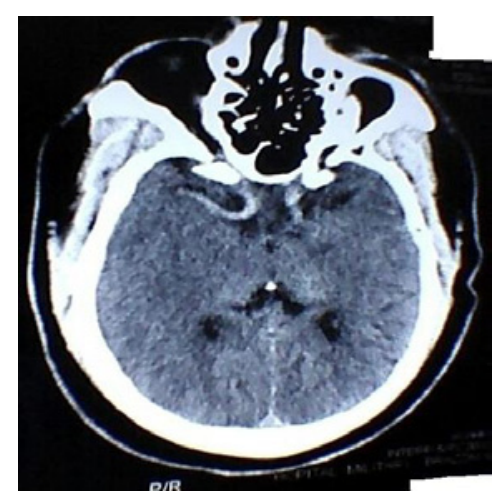

Figure 1: Visible Thrombus in carotid termination and middle cerebral artery.
Austin J Cerebrovasc Dis \& Stroke - Volume 4 Issue 3 - 2017 ISSN : 2381-9103 | www.austinpublishing group.com Ossou-Nguiet et al. (C) All rights are reserved
Citation: Ossou-Nguiet PM, Sossoumihen LL, Matali E, Mpandzou GA, Motoula Latou DH, Sounga Bandzouzi EP, et al. Stroke in Sub-Saharan Africa, from Thrombolysis to Decompressive Craniectomy: Case Report. Austin J Cerebrovasc Dis \& Stroke. 2017; 4(3): 1064. 


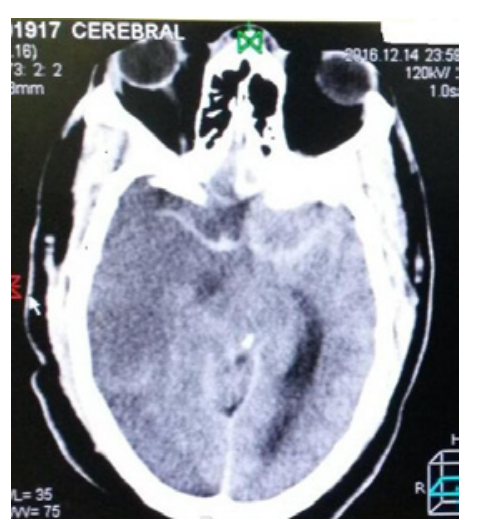

Figure 2A: Visible Thrombus in middle cerebral artery and malignant infarction.

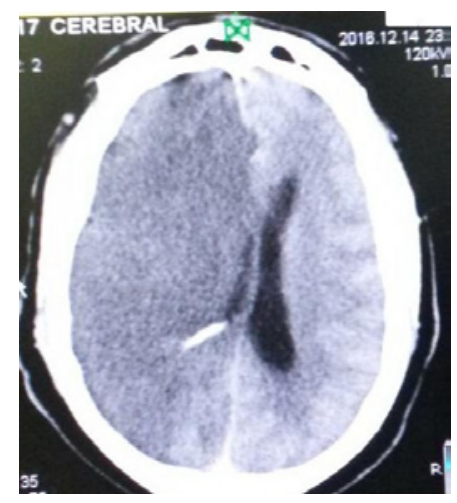

Figure 2B: Malignant infarction and mass effect.

there are very few countries with a stroke unit. In Congo unpublished data show that mortality decreased from $27 \%$ before to $14 \%$ after the set up of stroke unit.

Regarding on IV thrombolysis, its effectiveness has been proven since the publication of the results of the NINDS study in 1995 [9], within 3 hours, and then between 3:00 and 4:30 by ECASS III [10] in 2008. High income countries have included thrombolysis in their current practice, while in sub-Saharan Africa, outside of South Africa, no country is performing thrombolysis on patient series. Only a few cases are reported. This is due to several factors: the lack of trained human resources in vascular neurology, the absence of neurovascular units and the high cost of rt-PA [6]. Current case is the second thrombolysis in Congo.

Our patient required treatment with mechanical thrombectomy due to the occlusion of the carotid termination and the middle cerebral artery. Since the publication of the results of the MRCLEAN, ESCAPE, EXTEND, REVASCAT and SWIFT studies, thrombectomy is indicated and practiced in stroke centers in high income countries [11]. Its indications are well codified and require expertise, a multidisciplinary team and expensive equipment, which make it very difficult to access for patients in sub-Saharan Africa, as in Congo.

Decompressive craniectomy showed to be lifesaving and increasing the chance of good outcome [12]. However, after IV thrombolysis, despite short half-life of rt-PA, it's the thrombolytic effect may persist for up to 24-48 hours [13], which increases the hemorrhagic risk for decompressive craniectomy during this period. Also the clinical severity with NIHSS at 24, signs of cerebral herniation and massive infarction at the time of second CT scan have justified our attitude against decompressive craniectomy for our patient.

\section{Conclusion}

The implementation of the stroke unit in Brazzaville, allows the realization of IV thrombolysis. Mechanical thrombectomy, currently indicate alone or associated with IV thrombolysis, remains the treatment of choice for occlusions of the proximal arteries such as the carotid, middle cerebral artery and basilar trunk. The indication of decompressive craniectomy after unsuccessful IV thrombolysis should be confirm with caution and not indicated within 24 hours.

\section{References}

1. Hillmann S, Wiedmann S, Rücker V, Berger K, Nabavi D, Bruder I, et al. Stroke unit care in Germany: the German stroke registers study group (ADSR). BMCNeurol. 2017; 17: 49.

2. Catanese L, Tarsia Jand Fisher M. Acute Ischemic Stroke Therapy Overview. Circ Res. 2017; 120: 541-558.

3. Feigin VL, Forouzanfar MH, Krishnamurthi R, Mensah GA, Connor M, Bennett DA, et al. Global Burden of Diseases, Injuries, and Risk Factors Study 2010 (GBD 2010) and the GBD Stroke Experts Group. Global and regional burden of stroke during 1990-2010: findings from the Global Burden of Disease Study 2010. Lancet. 2014; 383: 245-254.

4. Lopez AD, Mathers CD, Ezzati M, Jamison DT, Murray CJ. Global and regional burden of disease and risk factors, 2001: systematic analysis of population health data. Lancet. 2006; 367: 1747-1757.

5. Adoukonou TA, Vallat JM, Joubert J, Macian F, Kabore R, Magy L, et al. Management of stroke in sub-Saharan Africa: current issues. Rev Neurol (Paris). 2010; 166: 882-893.

6. Ossou-Nguiet PM, Otiobanda GF, Mawandza PD, Ikama MS, Ellenga-Mbolla $\mathrm{BF}$, Ondze-Kafata LI, et al. Accessibility to rt-PA in Sub-Saharan Africa, Congolese stroke unit experience: Call for an urgent action. Int J Stroke. 2016; 11: NP30-1.

7. Langhorne P. Collaborative systematic review of the randomised trials of organised inpatient (stroke unit) care after stroke. Stroke Unit Trialists' Collaboration. BMJ. 1997; 314: 1151-1159.

8. Ringelstein $\mathrm{EB}$, Chamorro $\mathrm{A}$, Kaste $\mathrm{M}$, Langhorne $\mathrm{P}$, Leys $\mathrm{D}$, Lyrer $\mathrm{P}$ et al. ESO Stroke Unit Certification Committee European Stroke Organisation recommendations to establish a stroke unit and stroke center. Stroke. 2013; 44: 828-840.

9. Tissue plasminogen activator for acute ischemic stroke. The National Institute of Neurological Disorders and Stroke rt-PA Stroke Study Group. NEngl J Med. 1995; 333: 1581-1587.

10. Hacke W, Kaste M, Bluhmki E, Brozman M, Dávalos A, Guidetti D, et al. ECASS Investigators. Thrombolysis with alteplase 3 to 4.5 hours after acute ischemic stroke. N Engl J Med. 2008; 359: 1317-1329.

11. Wahlgren N, Moreira T, Michel P, Steiner T, Jansen O, Cognard C, et al. Mechanical thrombectomy in acute ischemic stroke: Consensus statement by ESO-Karolinska Stroke Update 2014/2015, supported by ESO, ESMINT, ESNR and EAN. Int J Stroke. 2016;11: 134-147.

12. Vahedi K, Hofmeijer J, Juettler E, Vicaut E, George B, Algra A, et al. Early decompressive surgery in malignant infarction of the middle cerebral artery: a pooled analysis of three randomized controlled trials. Lancet Neurol. 2007; 6: $215-222$.

13. Baharvahdat $\mathrm{H}$, Etemadrezaie $\mathrm{H}$, Zabyhian S, Valipour Z, Ganjeifar B, Mousavi Mirzaye SM, et al. Decompressive craniectomy after unsuccessful intravenous thrombolysis of malignant cerebral infarction. Iran J Neurol. 2014 ; 13:101-104. 